\title{
Capillary telangiectasia of the brainstem: MR features
}

\author{
Franz A. Fellner ${ }^{1,2 *}$ and Christine M. Fellner ${ }^{1}$
}

${ }^{1}$ Central Radiology Institute, Kepler University Hospital, Medical Faculty of the Johannes Kepler University, Linz, Austria

${ }^{2}$ Medical Faculty of the Friedrich-Alexander-University of Erlangen-Nürnberg, Germany

Cerebral vascular malformations are usually divided into arteriovenous malformations, developmental venous anomalies, cavernous angiomas and capillary telangiectasias with capillary telangiectasias accounting for $16 \%-20 \%$ of all vascular malformations at autopsy studies [1]. Capillary telangiectasias primarily occur in the brainstem and consist of numerous thin-walled vessels separated by normal brain parenchyma [2]. About two thirds of these lesions show an enlarged draining vein extending from the lesion to the surface of the pons [2-4]. To the present state of knowledge telangiectasias maybe acquired lesions rather than developmental lesions, which is supported by autopsy studies suggesting that capillary telangiectasia is most prevalent in adults [5]. Magnetic resonance (MR) imaging is the modality of choice in the visualization of these lesions, which are not seen in catheter angiography.

Figure 1 shows typical features of a capillary teleangiectasia as a well-defined lesion with a typical location in the right side of the pons. The lesion in this case has a diameter of about $2 \mathrm{~cm}$ without any mass

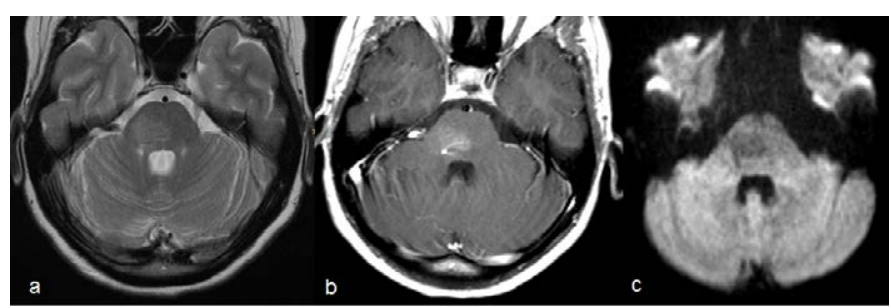

Figure 1. Capillary telangiectasia of the pons. T2-weighted TSE image shows an area with moderately increased signal in the right side of the pons (a). Gd-enhanced T1-weighted SE image reveals significant contrast enhancement (b). On diffusion-weighted MR (b value $=$ $1000 \mathrm{~s} / \mathrm{mm}^{2}$ ) the lesion is slightly hypointense (c).

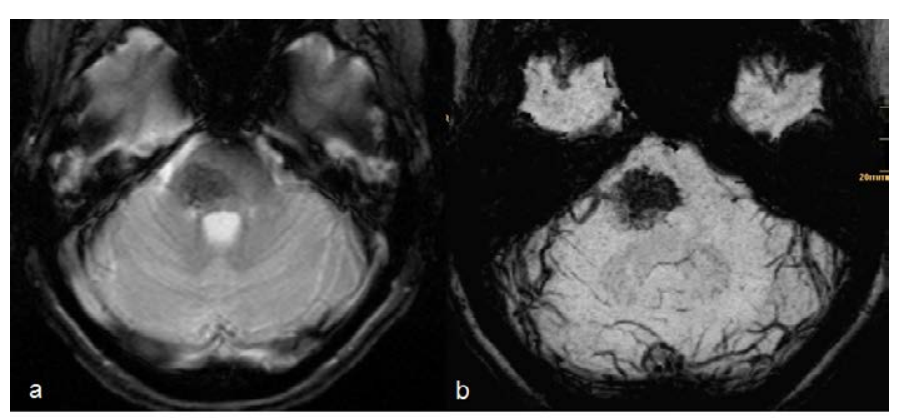

Figure 2. T2*-weighted conventional GRE shows the typical hypointensity of this lesion (a). Susceptibility weighted imaging (minimal intensity projection) allows superior delineation of the capillary telangiectasia in comparison to $\mathrm{T} 2 *$-weighted conventional GRE (b). effect. An associated enlarged draining vein was seen in the gadolinium enhanced sequence.

On $\mathrm{T} 2{ }^{*}$-weighted gradient-echo sequences these lesions present with low signal. Considering the high sensitivity of susceptibilityweighted imaging (SWI) for low-flow-vessels as occurring in vascular malformation the lesion consistently presents homogenously hypointense on SWI with sharp margins, much better demarcated than on conventional T2*-weighted GRE images (Figure 2 ).

Furthermore, a relevant feature is their behaviour on diffusionweighted images (Figure 1c) which may increase the specificity of MR in the diagnosis of such lesions. We could show in one case that capillary telangiectasias tend to show increased diffusion [6,7]. Unlike reduced diffusion high diffusion is rarely found on MR imaging. It can be seen in cerebrospinal fluid, vessels or rare pathological findings, e.g. ganglioglioma or cortical dysplasia [8].

With regard to frequent misinterpretation as tumor, ischemia or inflammation and particularly considering the high risk of brainstem biopsy for the patient it is imperative to establish reliable criteria for diagnosing vascular malformations.

\section{References}

1. Chaloupka JC, Huddle DC (1998) Classification of vascular malformations of the central nervous system. Neuroimaging Clin N Am 8: 295-321. [Crossref]

2. Barr RM, Dillon WP, Wilson CB (1996) Slow-Flow vascular malformations of the pons: capillary telangiectasias? AJNR Am J Neuroradiol 17: 71-78. [Crossref]

3. Castillo M, Morrison T, Shaw JA, Bouldin TW (2001) MR imaging and histologic features of capillary telangiectasia of the basal ganglia. AJNR Am J Neuroradiol 22: 1553-1555. [Crossref]

4. Lee RR, Becher MW, Benson ML, Rigamonti D (1997) Brain capillary telangiectasia MR imaging appearance and clinicohistopathologic findings. Radiology 205: 797-805. [Crossref]

5. Guibaud L, Pelizzari M, Guibal AL, Pracros JP, Rousselle C (1996) Slow-flow vascular malformation of the pons: congenital or acquired capillary telangiectasia. AJNR Am J Neuroradiol 17: 1798-1799. [Crossref]

6. Küker W, Nacimiento W, Block F, Thron A (2000) Presumed capillary telangiectasia of the pons: MRI and follow-up. Eur Radiol 10: 945-950. [Crossref]

Correspondence to: Franz A. Fellner, Central Radiology Institute, Kepler University Hospital, Medical Faculty of the Johannes Kepler University, Linz, Austria, Medical Faculty of the Friedrich-Alexander-University of ErlangenNürnberg, Germany, E-mail: franz.fellner@kepleruniklinikum.at

Received: April 04, 2017; Accepted: April 18, 2017; Published: April 21, 2017 
7. Fellner FA, Frei J, Mölzer G (2004) A new MR criterion in the diagnosis of capillary telangiectasis of the brain stem. Rofo 176: 1846-1848. [Crossref]
8. Pillai JJ, Hessler RB, Allison JD, Park YD, Lee MR, et al. (2002) Advanced MR imaging of cortical dysplasia with or without neoplasm: a report of two cases. AJNR Am J Neuroradiol 23: 686-1691. [Crossref]

Copyright: (C2017 Fellner FA. This is an open-access article distributed under the terms of the Creative Commons Attribution License, which permits unrestricted use, distribution, and reproduction in any medium, provided the original author and source are credited. 